\title{
Effect of Temperature on 60nm and 100nm Nanosphere Size Standard using Dynamic Light Scattering
}

\author{
Nor Dyana Zakaria, Izzati Zahidah Abdul Karim, Azimah Ahmad, Md. Sohrab Hossain, \\ Venugopal Balakrishnan
}

\begin{abstract}
It is difficult to use kinetic motion as a measurement tool without temperature affecting the results. In this study, the size of a known nanosphere was used to monitor the effect of temperature towards particle size determination using dynamic light scattering principles. Temperature deviations are always picked up by size measurement using the principle of Brownian motion. The particle size of $60 \mathrm{~nm}$ and $100 \mathrm{~nm}$ polystyrene latex nanoparticles in 10mM NaCl solution was measured at four different temperatures set points of 20, 25, 30, 35 and $40^{\circ} \mathrm{C}$ using dynamic light scattering mechanism. As a result, the size of polystyrene latex nanoparticles was increased with the increases of the temperature. Therefore, for particle size analysis using dynamic light scattering mechanism the temperature of the test must be maintained at $25^{\circ} \mathrm{C}$ in order to obtain accurate measurement.
\end{abstract}

Keywords : Particles size, temperature, dynamic light scattering.

\section{INTRODUCTION}

$\mathrm{T}$ emperature plays a vital role in optimization of product properties in a manufacturing process. It influences the growth of particle during the phase transitions of the materials, where kinetics and thermodynamic of the particle plays a role [1]. Raising the temperature improves the reactant particles kinetic energy, which increases the particles acceleration, thus enhances the frequency of collision. Therefore, the collision of particles occurs with more energy, which improves each collision's probability of success [2].

Dynamic light scattering (DLS), also known as photon correlation spectroscopy, is an effective method for

Revised Manuscript Received on December 30, 2019.

* Correspondence Author

Nor Dyana Zakaria*, Institute for Research in Molecular Medicine, Universiti Sains Malaysia, 11800 Penang, Malaysia. Email: nordyana@usm.my

Izzati Zahidah Adbul Karim, Institute for Research in Molecular Medicine, Universiti Sains Malaysia, 11800 Penang, Malaysia. Email: zatiez@usm.my

Azimah Ahmad, Institute for Research in Molecular Medicine, Universiti Sains Malaysia, 11800 Penang, Malaysia. Email: azimah1306@usm.my

Md. Sohrab Hossain, Environmental Technology Division, School of Industrial Technology, Universiti Sains Malaysia, 11800 USM, Penang, Malaysia. Email: sohrab@usm.my

Venugopal Balakrishnan*, Institute for Research in Molecular Medicine, Universiti Sains Malaysia, 11800 Penang, Malaysia. Email: venugopal@usm.my

(C) The Authors. Published by Blue Eyes Intelligence Engineering and Sciences Publication (BEIESP). This is an open access article under the CC BY-NC-ND license (http://creativecommons.org/licenses/by-nc-nd/4.0/) characterizing the size of molecules in solutions and colloidal dispersions to illuminate random motion of particles or molecules under Brownian motion [3]. Brownian motion is the random particle movement due to the solvent molecules surrounding them being bombarded. It indicates that the particles fluctuate continuously affect the intensity of the scattering. The fluctuation of the scattering intensity is due to the time taken by a molecule at a specific wavelength to travel for a significant distance. The change of the particle position is correlated to the size of the particle. According to Brownian motion the smaller size particles travel faster compared to larger size particles. The connection between the size of particle and acceleration is described clearly in Stokes-Einstein law [4], as shown in equation (1).

$$
D=\frac{K_{b} T}{6 \pi \eta R_{h}}
$$

Where $\mathrm{R}_{\mathrm{h}}=$ hydrodynamic radius, $\mathrm{D}=$ diffusion coefficient of particles, $\mathrm{T}$ =temperature, $\mathrm{K}_{\mathrm{b}}=$ Boltzmann constant and $\eta=$ dynamic viscosity of the continuous phase. In the present study, using known polystyrene latex nanoparticles $(60 \mathrm{~nm}$ and $100 \mathrm{~nm}$ ) the temperature affecting the size was monitored. The DLS measurement was carried out at five different points of temperature, which are ranging from 20 $40^{\circ} \mathrm{C}$.

\section{METHODOLOGY}

\section{A. Instrumentation setting}

DLS analysis were performed using a Zetasizer, Model ZEN 3600, Nanoseries, Malvern Instruments. The measurement of the particle size was conducted using laser at fixed angle of $173^{\circ}$ with $633 \mathrm{~nm}$ of wavelength.

\section{B. Nanoparticle preparation}

The suspension of polystyrene latex nanoparticles with mean diameter of $60 \mathrm{~nm}$ and $100 \mathrm{~nm}$ were used in this study (Thermo Scientific). The samples were prepared with 1 drop of polystyrene latex nanoparticles and diluted in $1 \mathrm{ml}$ of filtered aqueous $10 \mathrm{mM}$ sodium chloride $(\mathrm{NaCl})$ in a polystyrene cuvette. The analysis was performed at five different point of temperature at $20^{\circ} \mathrm{C}, 25^{\circ} \mathrm{C}, 30^{\circ} \mathrm{C}, 35^{\circ} \mathrm{C}$ and $40^{\circ} \mathrm{C}$. Measurements were repeated three times in order to determine the standard deviation and measurement of uncertainty for $60 \mathrm{~nm}$ and $100 \mathrm{~nm}$ of polystyrene latex nanoparticles. 


\section{RESULTS AND DISCUSSION}

The particles size measurement was performed using 60 $\mathrm{nm}$ and $100 \mathrm{~nm}$ polystyrene latex nanoparticles. Five different point of temperature setting were used to analyze the dynamic light scattering, which are $20^{\circ} \mathrm{C}, 25^{\circ} \mathrm{C}, 30^{\circ} \mathrm{C}$, $35^{\circ} \mathrm{C}$ and $40^{\circ} \mathrm{C}$. Figure 1 show the calculated diameters of the polystyrene latex nanoparticles $60 \mathrm{~nm}$ were $63.9 \pm 5.5$, $66.4 \pm 5.4, \quad 69.1 \pm 5.4, \quad 69.2 \pm 5.4$ and $70.3 \pm 5.4 \mathrm{~nm}$ for temperature $20^{\circ} \mathrm{C}, 25^{\circ} \mathrm{C}, 30^{\circ} \mathrm{C}, 35^{\circ} \mathrm{C}$ and $40^{\circ} \mathrm{C}$, respectively. Meanwhile, the calculated diameters of polystyrene latex nanoparticles $100 \mathrm{~nm}$ were $102.3 \pm 6.7,104.4 \pm 6.6,105.4 \pm 6.6$, 108.2 \pm 6.6 and $108.7 \pm 6.6 \mathrm{~nm}$ for temperature $20^{\circ} \mathrm{C}, 25^{\circ} \mathrm{C}$, $30^{\circ} \mathrm{C}, 35^{\circ} \mathrm{C}$ and $40^{\circ} \mathrm{C}$, respectively are shown in Figure 2. Figure 3 indicates that the size of $60 \mathrm{~nm}$ and $100 \mathrm{~nm}$ polystyrene latex nanoparticles increased according to the increment of the temperature in DLS system. Both nanosphere fall in the acceptable hydrodynamic diameter range for 20,35 and $30^{\circ} \mathrm{C}$ experimental reading. However, the hydrodynamic diameter for 35 and $40^{\circ} \mathrm{C}$ of $60 \mathrm{~nm}$ and $100 \mathrm{~nm}$ nanosphere was out of range. The increasing hydrodynamic diameter is due to the effect of increasing temperature, which increases the colliding particles. The collision requires high quantity of energy for an efficient collision. Therefore, there will be more particles with higher activation energy [5]. According to Stokes-Einstein Law, during the increased in temperature all other constant will remain same except for temperature will change. The increment of the temperature is directly proportional to the hydrodynamic diameter of the particles [4]. Besides, the nanoparticle size enlargement occurs by one of two processes. The first process is Ostwald ripening which is known for soluble materials, where the rate of growth of large particles are dependent to the smaller particle dissolution [1]. The second process is oriented attachment, which is known for soluble crystals, where the size of the particle is dependent to the fusion of the smaller particles [6]. Furthermore, both above processes are dependent on the temperature. The effect of temperature on Ostwald ripening process is dependent to three factors, which are coefficient of growth rate, solubility and interfacial energy. Meanwhile, in the process of oriented attachment the effect of temperature is dependent to the surface energy and interphase boundary [7].

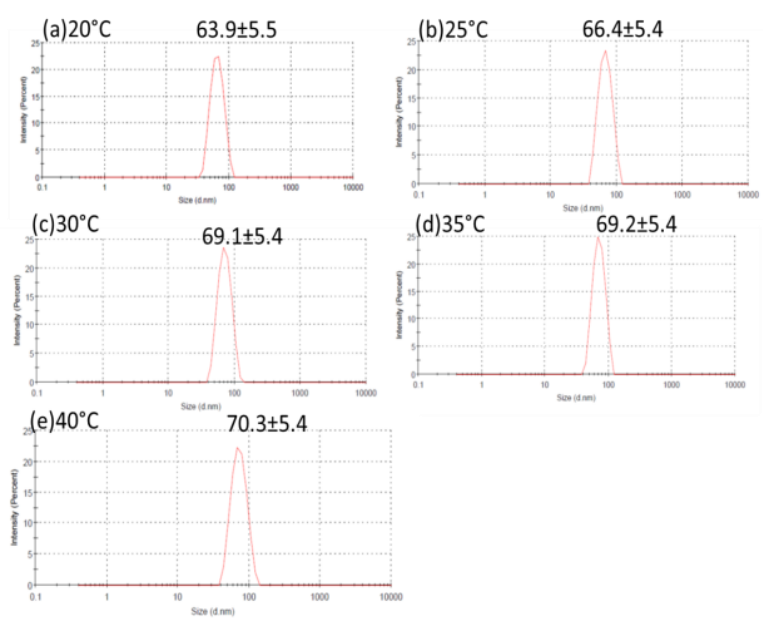

Fig. 1. Particles size analyzer graph for $60 \mathrm{~nm}$
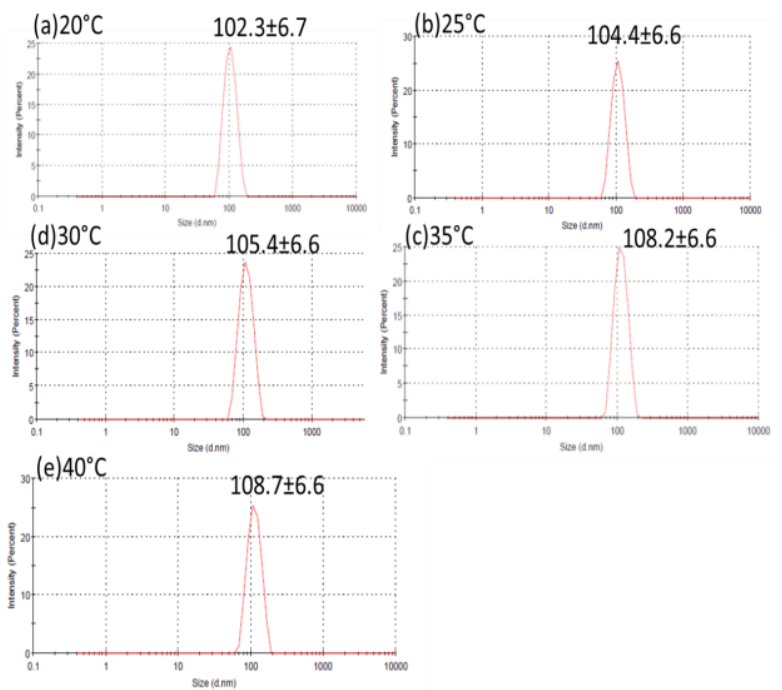

Fig. 2. Particles size analyzer graph for $100 \mathrm{~nm}$

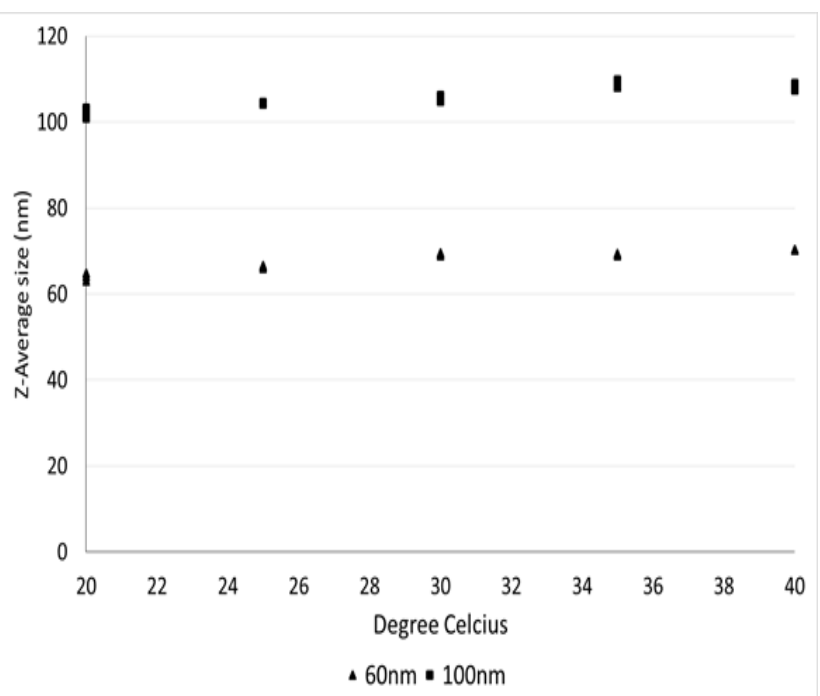

Fig. 3. Verifying the temperature stability of the DLS

\section{CONCLUSION}

As in summary, using the DLS the size of 60 and 100nm of polystyrene latex nanoparticles increased with the increase of temperature from 20, 25, 30, 35 and $40^{\circ} \mathrm{C}$. The optimal temperature is $25^{\circ} \mathrm{C}$ as it mimics the standard temperature in a laboratory. The obtained hydrodynamic diameter for $60 \mathrm{~nm}$ and 100nm nanosphere was acceptable and within the acceptance criteria.

\section{ACKNOWLEDGMENT}

I would like to thank Division of Research and Innovation of Universiti Sains Malaysia for providing the financial assistance in order to complete the project (1001.JPNP.AUPQ001). 


\section{REFERENCES}

1. Madras, G. and B.J. McCoy, Temperature effects during Ostwald ripening. The Journal of chemical physics, 2003. 119(3): p. 1683-1693.

2. $\mathrm{Qu}, \mathrm{Y}$., et al., The effect of reaction temperature on the particle size, structure and magnetic properties of coprecipitated CoFe2O4 nanoparticles. Materials Letters, 2006. 60(29-30): p. 3548-3552.

3. Beliciu, C. and C. Moraru, Effect of solvent and temperature on the size distribution of casein micelles measured by dynamic light scattering. Journal of dairy science, 2009. 92(5): p. 1829-1839.

4. Maxit, B., Particle size measurements of dark and concentrated dispersions by dynamic light scattering. tc, 2009. 10: p. 6s.

5. Liu, H., et al., Effect of temperature on the size of biosynthesized silver nanoparticle: deep insight into microscopic kinetics analysis. Arabian Journal of Chemistry, 2017.

6. Xue, X., et al., Crystal growth by oriented attachment: kinetic models and control factors. CrystEngComm, 2014. 16(8): p. 1419-1429.

7. Lv, W., et al., Understanding the oriented-attachment growth of nanocrystals from an energy point of view: a review. Nanoscale, 2014. 6(5): p. 2531-2547.

\section{AUTHORS PROFILE}

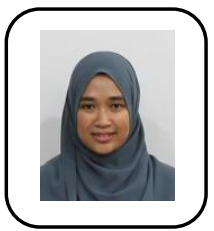

Nor Dyana Zakaria, working as a Research Officer a Universiti Sains Malaysia. She received her M. Sc (Analytical Chemistry) and B. Sc. (Chemistry) from Universiti Putra Malaysia. Her research focus is in Nanoparticles for biomedical applications.

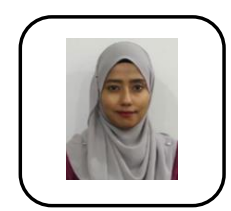

Izzati Zahidah, is a Medical Laboratory Technologist. She has a Diploma in Medical Laboratory from Pusat Teknologi \& Pengurusan Lanjutan (PTPL) College.

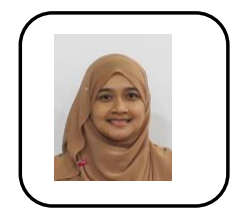

Azimah Ahmadis, received B. Sc (Hons) Applied Science (Industrial Chemistry) in Sept 2009 at Universiti Sains Malaysai. Currently Science officer at INFORMM, USM.

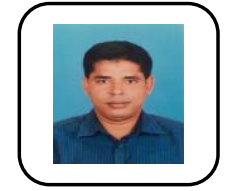

Dr. Md. Sohrab Hossain, is currently working as a senior lecturer in the field of environmental technology at Universiti Sains Malaysia. Dr. Sohrab has obtained his $\mathrm{PhD}$ degree in Environmental Technology from University Sains Malaysia. He has expertise in hazardous waste management, wastewater treatment, heavy metals separation and recovery and supercritical fluids technology with over 60 publications in ISI and Scopus indexed journals, book chapters, and presentation at international conferences in the area of hazardous waste and wastewater treatment.

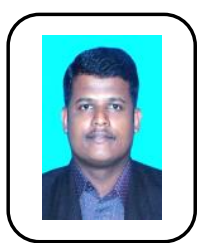

indexed journals.

Dr. Venugopal Balakrishnan, Associate Professor, is currently working as lecturer in the field of biochemistry and molecular biology at Universiti Sains Malaysia. He has obtained his $\mathrm{PhD}$ in Molecular and Cellular Biology from Universiti Sains Malaysia. He has expertise in cancer biology, environmental microbiology, nanotechnology and biological waste management. He has published numerous manuscript ISI and Scopus 